\title{
WAYS TO INCREASE THE INCLUSIVE COMPETENCE OF PEDAGOGICAL STAFF OF SPECIAL NEEDS SUPPORT TEAM
}

\author{
Olena Martynchuk \\ Borys Grinchenko Kyiv University, Ukraine \\ Tatiana Skrypnyk \\ Borys Grinchenko Kyiv University, Ukraine
}

Julia Naida

Borys Grinchenko Kyiv University, Ukraine

Natalia Sofiy

Ukrainian Institute of Education Development, Ukraine

\begin{abstract}
Inclusive education in Ukraine at the legislative level started more than 10 years ago, but analytical monitoring studies indicate that the level of education for children with SEN is unsatisfactory. The lack of an inclusive learning strategy and low level of teachers 'readiness to carry out the educational process for children with SEN together with their peers may be factors in this situation.

The purpose of the study is to develop and implement an algorithm for enhancing the competence of teachers of inclusive classes. We conducted a training program in eight educational institutions (10 IEP teams), aimed at increasing the level of team interaction and inclusive competence of specialists. To assess the process of inclusive competence s formation before and after the training program, we used Org-EIQ methodology, motivational orientation test, and teacher self-assessment method «Professional Development Tool for Improving the Quality of Practice in Primary School». As a result, all teachers have achieved a significant increase in the effectiveness of interdisciplinary support for children with special needs, which have reflected in the positive changes that have occurred in teachers at the professional, interpersonal and personal levels.
\end{abstract}

Keywords: expert coaching, IEP team, teacher's competence, special needs, team management model.

\section{Introduction}

Strengthening international focus at inclusiveness has caused essential changes and development of educational policy and practice, especially in a field of education for children with special educational needs (Ainscow, 2010; Haug, 2017). Nowadays the large-scale national educational reform takes place in Ukraine, which is aimed at the New Ukrainian School concept realization. This 
reform implements more inclusive ideology and acceptance of diversity (Cabinet of Ministers of Ukraine [CMU], 2016). However, there are numerous barriers on the way to provide quality inclusive education - providing the equal rights for students with special educational needs (SEN).

Following factors are relevant for Ukrainian society: rather high level of consciousness regarding the acceptance of inclusive values (European Research Association [ERA], 2012); developed theory on inclusive education (Kolupayeva, 2009; Kolupayeva \& Taranchenko, 2016); clearly developed educational policy (Grinevich, 2015). However, Ukraine does not provide quality and sufficient inclusive practice yet. There is number of studies, where the gap between the theory and practice is discussed (Piters, 2018; Alishavskane, Onufrik, \& Florian, 2019).

Now there is a lack of empirical studies, which are focused on the search of the ways of improving inclusive competence of teachers who provide psychological-pedagogical support for children with special educational needs in the school educational environment. In spite of obvious advantages of the team work and critical importance of the capacities of specialists and parents for team interactions as the main factor of the effective support of students with special educational needs in the educational process (Ilik \& Sar1, 2017), this format of workin Ukraine remains underworked out in the educational inclusive environment. Therefore, there is a need to deeper understanding and in the development of strategies and technologies of in-service training of the support teams, which provide psychological-pedagogical support of students with special educational needs. In order to meet this need, we set up the following goal of our study - to develop the program for in-service training of the members of Individual Educational Program teams (support team), which is based on the model of effective team management of Hackman (Hackman, 2002).

\section{Literature Review}

Analysis of special literature demonstrates that education is extremely important for the provision of sustainable society development and equal opportunities for all children, including children with special educational needs (Dumcius, Peeters, Hayes, VanLandeghem, Siarova, Peciukonyté, Ceneric, \& Hulpia, 2014). Number of researchers, organizations and policy-makers achieved the consensus that quality of education depends from the well-educated and competent cadres (Dumcius et al., 2014). Importance of high qualification of professionals is recognized at the European level by the priorities of the strategic cooperation in a field of education and professional training (European Commission, 2015). It is mentioned there that professionalism of cadres is one of 
the key tasks in the work in educational field, which is now the important issue of policy agenda in Ukraine. Because of this, the Government of Ukraine has implemented important initiatives on reforming educational sector, represented in the Law “On Education” (Verkhovna Rada of Ukraine [VRU], 2017) and the New Ukrainian School concept (CMU, 2016). UNICEF in Ukraine supports this process, in particular through the number of studies, which provided the analysis of the system of pre-school and inclusive education in Ukraine (Piters, 2018; Alishavskane et al., 2019).

Thus, the study on the quality of pre-school education which was conducted according to the European quality framework for early childhood education and care (EQF) identified activities, necessary for improving the system of teachers` competencies, among them - improving the system of on-going professional development for pre-school, primary and secondary school teachers, special teachers, methodologists, school directors and other educators (with the focus on child-centered learning as well as on inclusive approach), and the main focus of attention should be paid to the analysis of pedagogical practice within pedagogical mentoring (Piters, 2018).

In-service teacher training system in Ukraine has remained unified until the recent days and included participation at the in-service courses once per five years. However, taking into account current rapid changes, such a frequency (one time per five years) has not longer met the needs of the time and teachers` requests (Sofiy, 2017), that is why the government of Ukraine has adopted the new Procedure of in-service training of teachers and faculty members (CMU, 2019), where different forms of in-service training and on-going nature of professional development has been adopted. One of the tasks of in-service teacher training is developing inclusive competence through different forms, including on-job training (CMU, 2019). Therefore, there is an interest to the studies, which present different aspects of developing inclusive competence of the teams of psychological-pedagogical support of children with special educational needs in Ukraine.

Existing studies (Loreman, McGhie-Richmond, Kolupayeva, Taranchenko, Mazin, \& Crocker, 2016; Martynchuk, 2018) identify some of the important components of the process of organization of educational environment, which are necessary to avoid the mistakes and to provide effective inclusive learning. The most profound is the study conducted by European Agency for Special Needs and Inclusive Education during 2009-2012 within the project "Teacher Education for Inclusion". The project was aimed at identification of the main teachers" competences, necessary for success fulprofessional work at schools in XXI century. The following competences have been identified within the study: team work with parents and other specialists, on-going professional and personal development. 
Martynchuk et al., 2020. Ways to Increase the Inclusive Competence of Pedagogical Staff of Special Needs Support Team

Meta-analytical study (Hattie, 2009) identifies four criteria of the successful teachers`work:

1) PriorAchievement (the levels of students at the start);

2) Targeted Learning (the desired levels at the end);

3) Progression (the rate of progress from the start to the end);

4) Teacher Collaboration. The fourth criterion -Teacher Collaborationmeans uniting the potential of the members of IEP team, which includes joint discussion and planning, identification of success criteria, ways of achieving learning progress, expectations for students, active parents participation regarding goals` identification and realization (Stroggilos \& Xanthacou, 2006). Other studies (Kurth \& Foley, 2014; Rotte, 2014) of teachers` abilities to implement teaching process based of partnership interactions, communication with colleagues, students and their parents are the most important qualities for effective teachers.

At the same time the researchers identify some of the disadvantages of IEP team interactions, in particular: lack of their attention to the planning of joint work and assessment of its results; there is a tendency to act separately, not together (Strogilos, Stefanidis, \& Tragoulia, 2016). Thus, the lack of mutual understanding between some of the specialists of the team (speech therapist and regular teacher) and their insufficient understanding of the content of professional work and professional limits (Hersh, O'Rourke, \& Lewis, 2013).

Studies of the successful practice of inclusive classrooms demonstrate that in addition to the positive attitudes to inclusive teaching teachers have to possess certain competence, which include their ability to work in the teams (Hackman, 2002; Stroggilos et al., 2006).

Therefore, the context review of the studies on teachers competencies necessary for their work in inclusive environment is the basis for researchers who wish to study the ways of developing inclusive competence of teachers - the members of IEP team in inclusive educational environment.

The goal of this research is to study and to justify effective ways of improving capacities of IEP team members towards team collaboration as the transversal skill, which will provide effective support to students with special educational needs at each of the stage of educational process. In our research we assumed that the level of inclusive competence of team members, their skills to work as a team will increase essentially the level of effectiveness of their work in supporting children with special educational needs in educational environment.

\section{Methodology}

Our research included three stages. At the first stage we explored the level of inclusive competence development of the members of pedagogical support 
teams; the goal of the second stage was to conduct their training according to the program developed by us, which was aimed at the increasing the level of inclusive competence (including ability to work in a team); at the third stage we studied the results of the training approach we used.

To realize the first stage, we used the methods, which allowed us to explore the level of inclusive competence`s development of the members of psychological-pedagogical team which provides additional support to children with special educational needs, in particular the level of development its components:

1) emotional and organizational skills (methodology Org-EIQ, Giorgi \& Maier,2014),

2) orientational motivations (test «TOM», Borgogni, Petita, \&Barbaranelli, 2014),

3) teachers`self-assessment according to seven areas: Interactions, Family and Community, Inclusion, Assessment and Planning, Teaching strategies, Learning Environment, and Professional Development(we adopted methodology of identification of teachers` self-assessment «Professional Development Tool for Improving the Quality of Practice in Primary School»). That study included only the specialists working in the school.

Selection of the mentioned above study methods is based on the characteristics of the teachers 'professional work in the inclusive school within interdisciplinary teams. As the result of our previous studies (Martynchuk, 2018) we identified that level of inclusive competency depends from emotional competency of teachers, which depends on the emotional intelligence and is based on it. Therefore, in our study we used the approach of Italian researchers G. Georgy and V. Maier (Giorgi \& Maier, 2014) for the studying emotional intelligence. This process is based on two theories: the theory of at-job effectiveness and the theory of organizational intelligence. Researchers affirm that organizational intelligence structurally relates to the individual emotional intelligence through "group" mechanism: other words, emotional intelligence is accumulated in a certain environment, where it becomes organizational one (Giorgi \& Maier, 2014). That theoretical statement was apobated and confirmed in the framework of our research (Martynchuk, 2018). The results of our research provided us the reasons to assume that emotional intelligence is the important part of inclusive competence and organizational intelligence is the core of the psychological-pedagogical team (support team), which supports the children with special educational needs.

While studying the level of development of inclusive competence of future educators from special team (Martynchuk, 2018), we used European valid methodology Org-EIO "Assessment of emotional intelligence" (authors: 
G. Georgi, V. Maier, adaptation for Ukraine has been made by V. Klymchuk and V. Gorbunova) to study emotional organizational intelligence (Giorgi \& Maier, 2014).

Teacher`s motivational orientations play an important role in the development of inclusive competence (Martynchuk, 2018) because motivation itself has a leading role in the person`s behavior structure and it is the driving force of human activities for achieving the specific goals. We used European valid methodology TMO test of Orientational Motivations" (authors: L. Borgoni, L. Petita, K. Barbarnelli, adapted for Ukraine by L. Burlachuk and Kh. Rakhubovska) to study orientational motivations. This test allowed to study the motivations which guide a behavior in the professional conditions (Borgoni et al., 2014).

While identifying the content of inclusive competence we used the study materials of International Step by Step Association (ISSA) - association, which works in a field of development of children aged from birth till 10 years old (preschool and primary school age) in more than 35 countries and promotes inclusive education ideas through its programs and projects, in particular: modified the methodology according to the objectives of our research, systematized the main statements which related to the knowledge and skills to provide effective support to children with SEN. We put ISSA principles of Quality Pedagogy as the basis of development of study methods, because these principles correspond with international tendencies in the inclusive culture and practice (Competent Educators of the 21st Century: Principles of Quality Pedagogy, 2009). ISSA principles of Quality Pedagogy include seven areas (interactions, family and community, inclusion, diversity and values of democracy, assessment and planning, teaching strategies, educational environment, and professional development), which are based on the recent studies in a field of quality pedagogy and correspond with the international tendencies in the field of providing educational services to children aged 3-10 years old (Tankersley et al., 2010). They als ocorrespond with the results of the study conducted by European Agency for Special Needs and Inclusive Education «Teacher Education for Inclusion» (EASNIE, 2012).

At the second stage of research we used such methods in the training program, as: team activities, group discussions, implementing the tasks in small groups, video analysis of participants`actions, reflective-analytical activities, team consistent coaching.

Duration of the Training program was 7 months, it took place from October 2018 till May 2019 (there was one month break from December 22, 2018 till January 21, 2019). Training program was provided in 8 schools for 10 teams, which provided psychological-pedagogical support to children with SEN. 
The third stage of our research envisioned confirmation of effectiveness of received results after implementation of training program. This confirmation has been done due to the developed semi-structured survey, self-reports of the teachers and data division by percentages to identify levels development of inclusive competence, which allowed to understand the level of teachers` and parents`satisfaction of team work`s quality as well as the changes in the educational process of children with SEN. To comprehend received results regarding development of teachers`inclusive competence we also used quality analysis.

To provide organizational impact on the level of team members` inclusive competence, we developed and implemented practice-oriented training program, which was focused not only at teachers, but also at parents of children with SEN. In total, 78 IEP team members, including 16 parents, 10 teachers, 8 teacher assistants, 8 psychologists, 8 speech therapists, 6 sports instructors, 9 special education teachers, 4 music teachers and 9 subject teachers, were involved in training program. The majority of all teachers - 53 outof 62 (85\%), had the experience of working with children with SEN; other just were informed that children with SEN will study in their classrooms.

The developed practice-oriented training program is based on the model of team effectiveness of R.Hackman (Fig. 1).

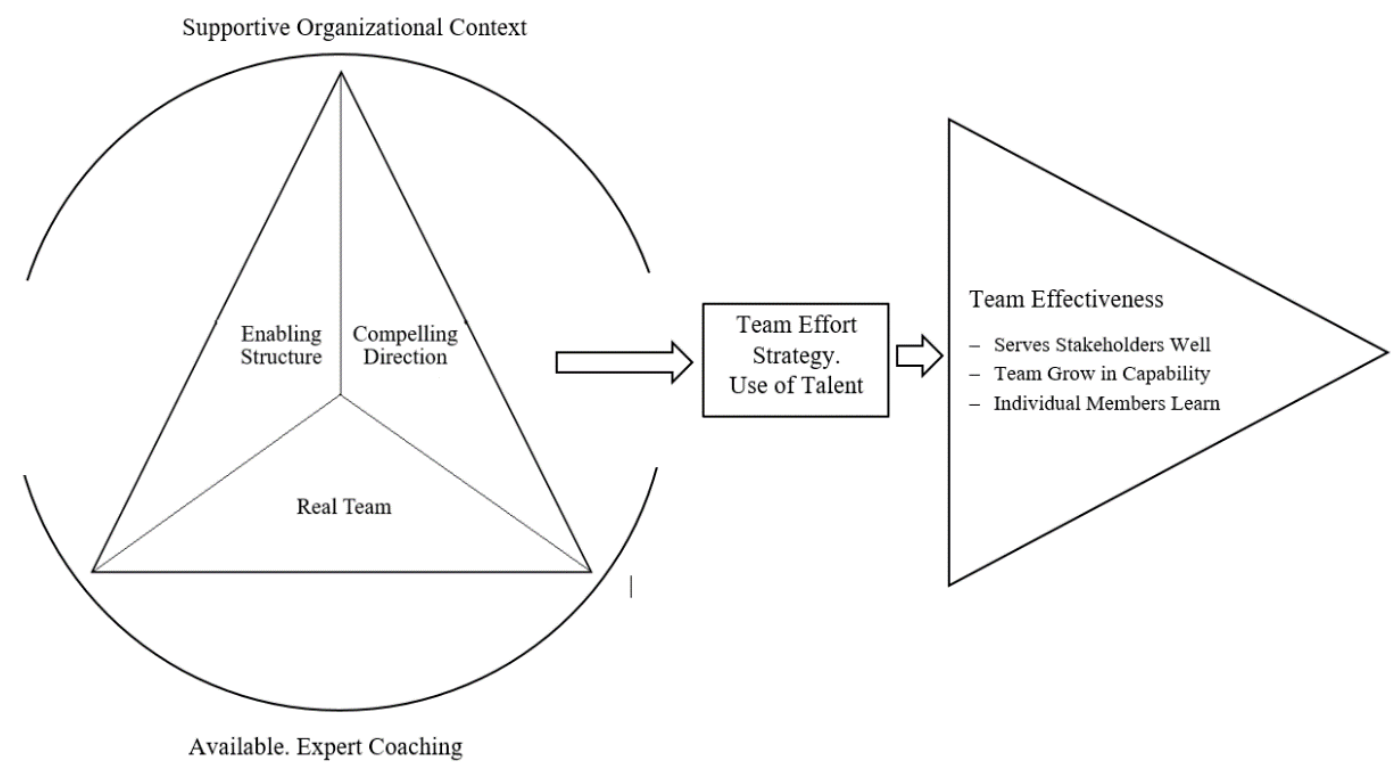

Figure 1 The model of team effectiveness (Hackman, 2002)

According to this model, in addition to professional competence (so called hard skills), there are also so called soft skills, which play an important role in the improving professional activities. One of the important soft skills is the capacity 
to work in a team. It is important to understand that all efforts of specialists can be false-start if the first stage does not happen: creation a team, team work, and regular mentoring. Only preparatory work, which includes thorough planning, common decision making, coordinated algorithm of actions, can provide successful realization of existing teachers `competencies and also improvement of their skills in a future. Regular interactions between team members enable synergetic effects, which influence on realization of potential opportunities of team members and essentially promote the common success.

Therefore, we are making in our study the main accent on the development of effective interactions between IEP team members. Our developmental impact to increase inclusive competence of IEP team members (teachers and parents) was based on the following group interactions ` principles: integration of professional and personal resources of each of the team members in the process of interactions; coordination of actions towards creating comfortable social environment based on individual approach to every child; establishing productive interactions with child`s family; coordination of efforts in the process of identification of criteria for assessment of effective education of children with SEN.

\section{Research results}

Diagnostic methodologies provide the results, which have been analyzed and interpreted to identify the main content of the training program.

According the methodology Org-EIQ, teachers demonstrated insufficient level of:

1) empathy as ability to listen to others, understand feelings and ideas of other people ( $\mathrm{n}=44,71 \%)$;

2) teachers` orientation on students, which is conditioned by teachers` efforts to manage educational process. Many of the teachers $(n=52$, 84\%) confessed they could not find common areas of understanding with students and their parents, could not provide constructive dialog with them, they did not feel they were respected either by students or their parents. The majority of teachers demonstrated lack of skills to cooperate and interact with people to achieve common goals according the indicator "Team work", they also were not able to stimulate others.

TOM test allowed to understand what kinds of orientational motivations are preferred by the teachers. Predominant level of orientational motivations ` development according to all scales (orientation on achievements, orientation on leadership, orientation on innovations, orientation on relationships) was the medium level. Orientation on relationships has little predominance comparing to other scales. Considering peculiarities of professional activities within the context of inclusive education (which are presented in details in the study of European 
Agency for Special Needs and Inclusive education within the «Teacher Education for Inclusion» project (2009-2012), we presumed that teachers should have a high level of motivational orientation on relationships and on the achievements to provide successful professional activities in the context of inclusive education.

The survey results according to methodology Instrument for professional development to increase the quality of primary teachers` work” identified the following levels of teachers` competencies according to different areas. 22 teachers $(35,5 \%)$ were assessed as «Inadequate» (practice, which is not oriented at the child); 28 teachers (45\%) received «Goodstart», which was a result of their efforts to master effective methods and approaches oriented on children; 2 teachers (3\%) were evaluated as «Quality practice» and «Moving forward» as the result of their believes in children`s potential, using all possibilities for professional development.

Quality analysis of the received results allowed us to understand that teachers of inclusive classrooms feel confusion regarding team work and lack of their confidence in their actions as well as lack of confidence towards children with SEN. Also, some negative attitude was identified towards psychologicalpedagogical team: the majority of teachers saw the team meetings as obligatory work rather than important condition of their successful work; teachers mentioned they could hardly find time for such meetings, that they would rather spend this time preparing for the next day or record school documentation.

Training program includedalternation of learning sessions and practical implementation of received knowledge and developed skills to gain the experience of team work directly in the educational process.

The central focuses of the practice-oriented training program were theoretical and practical aspects of the team support of children with SEN in the educational process, the role of each member of the team in this process.

The following team work skills were developed/improved as a part of the training program: developing respect and trust, flexibility of thinking and activation of creativity; active listening, coordination of different ideas, recording effective documentation.

In order to practice these skills four experts provided consistent coaching, which alternated with reflective-analytical activities. The most widespread scheme of the team work was using the experience members of the psychologicalpedagogical teams received at the training during their professional work, which allowed them critically reflect on it. During new training sessions, participants analyzed critically their new experience, where they tried to comprehend the factors of their successes and mistakes. Together with their coordinator and experts, all IEP members developed the rules for team work, established feedback, tried to focus on the mastering the modern approaches to the inclusive process at 
the level of all school. All of this supported the necessary level of motivation and joint intensions regarding development and realization educational environment.

As the result of studying the level of competencies of teachers in team work to support students with SEN after the training, we realized that teachers improved their level of knowledge and skills regarding team work with students, their parents and colleagues essentially.

Thus, according to the methodology Org-EIQ increasing the indicators according the position "social competence" was identified: the majority of specialists could better listen to other people, to understand their feeling and thoughts (77\%). High rating of indicator according the parameter "orientation at students, finding the common language with students and their parents, conducting constructive dialogue with them" was demonstrated by $84 \%$ of participants. The characteristic "ability to work in a team" demonstrated 93\% of teachers, which is 3.5 times more comparing with previous study results.

Because of TOM methodology we identified the essential improving of such indicators, as "Motivational orientation on achievements" and "Motivational orientation on innovations", which provided evidences teacher obtained more inspirations for innovative work, they started to use spontaneity and creativity, they demonstrated intensions to obtain new knowledge and new approaches as well as their willingness to change by themselves.

Methodology "Instrument of professional development to improve the quality of primary teachers" allowed us to identify essential improvement regarding indicators of professional development: ability to communicate effectively with parents, to use different opportunities to work in IEP teams as well as in other types of teams of teachers, to analyze and to discuss their challenges with colleagues, to monitor procedures, to use new methods of work to increase effectiveness of teaching students with SEN.

During analytical sessions and through their self-analysis participants of the training highly evaluated all three stages of mastering their new experience training sessions, practical implementation of their new knowledge, and further discussions. The joint conclusion was that a value of such a raining format was a team format and its on-going coach`s support.

Because of analytical sessions, majority of members of IEP teams (8 out of 10) recognized they not only couldn't work in a team, but also did not fully understand the content of such interactions: they did not use individual educational program (IEP) as the instrument of cooperation, did not try to build partnership with parents, were not interested in the colleagues`experience, did not coordinate short-term and long-term goals for children with SEN between ourselves and did not formulate SMART objectives in particular; they did not monitor the dynamics of development of these children either. Participants of the study recognized that one of the most negative consequences of such 
uncoordinated work was that they couldn't identify the content and the process of services`provision, which would meet the actual children`s needs. Therefore, those services were more formal and had a minimal use for children.

One of the most important conditions for establishing real team support for children with SEN was the existence of coordinator (case manager) in the support team. Because of coordinator of support team (IEP team), it`s meetings became more prepared and had more clear procedures, content and were organized appropriately. Team members also identified the second important innovation parents `role as partners. The majority of parents told they have never participated in the meetings with all professionals who worked with their child before. Usually they met individually with separate subject teachers who were working with their child. Such an experience was unusual both for the specialists as well as for parents, but implementation of equal interactions with parents was highly evaluated by all participants of the training program. Parents began to feel they can influence on the educational process of their children, they can make their choice regarding necessary methods, approaches and means, which can improve educational process for their children, to take an active role in the development and realization of learning and developmental goals for their children.

\section{Discussion}

The novelty of the approach is to educate teachers in the curriculum developed by our team program "Technology of team interaction of teachers of inclusive institutions", based on the team management model for significant achievements. Despite the obvious advantages of teamwork, this format of work in Ukraine is still not mastered in an inclusive educational environment.

The study`s results allowed us to make a conclusion that teachers have to master team interaction technology in order to be successful in working with children with SEN in inclusive educational environment. Establishing effective support teams essentially has changed the productivity of all IEP teams, which were involved in the study. Those changes, first of all, had their influence on increasing the positive dynamics of learning and development of children with SEN, and also on the level of satisfaction of the team members. All members of IEP teams assessed filling out the supportive documentation, planning and realization of partnership cooperation as the effective new experience.

Formative influence was done directly during the professional activity of teachers and was accompanied by regular expert coaching.

Received experience of the group work at the each stages of planning, realization and monitoring the process of support the students with SEN has been marked on the development of professional mastering of specialists, able to create modern educational environment, which corresponds with the existing challenges. 
Achievements of teachers who have been trained in a team-work are essentially distinguished and included the following: capacity to work with other specialists, to analyze students with SEN, to develop measurable, time-bounded, specific and achievable goals, to plan special support and role each of the members in this process; to develop authentic partnership relations with parents, to support interactions with the child`s family and other colleagues in the school and outside of school based on the respect; to create the conditions for communication and exchange of information with family members of students with PAC in educational environment, to discuss with them plans, rules, procedures, classroom activities. In the interviews with teachers they confessed that ability to communicate with families effectively was a big challenge for many of them.

According the teachers` survey results it becomes clear that we obtained skills which allowed us to create real support team (headed by coordinator), which began to realize inclusive process purposefully, consistently, with coordination and divisions of functions with teacher with active parents participation at all stages of developed algorithm of support providing. Such thoughtfully organization of the joint work had an impact on the increasing results of learning and development of children with SEN as well as on general classroom atmosphere - encouraging for all students, and also on the professional level of teachers.

\section{Conclusions}

The training program which was used in the process of development of teachers` inclusive competence has demonstrated its effectiveness, which was confirmed by diagnostic instruments and teachers` self-reports. Implemented work provided opportunities to identify two conditions necessary for training of teachers to work in the interdisciplinary teams:

1) when teachers will work as a team (without leaving their professional activities within psychological-pedagogical support);

2) providing consistent expert coaching, which allows step-by-step obtaining by teachers and parents the ability to organize and provide competent team support.

Making the conclusion, we have to say that study data testify the changing of nature of interactions between the support team members is the important condition for improving education for children with SEN and the quality of their parents` lives. 
SOCIETY. INTEGRATION. EDUCATION

Proceedings of the International Scientific Conference. Volume IV, May $22^{\text {th }}-23^{\text {th }}, 2020.70-83$

\section{References}

Ainscow, M. (2010). Developing Inclusive Education Systems: The Role of Organisational Cultures and Leadership. London: Taylor \& Francis.

Alishavskane, S., Onufrik, M., \& Florian, L. (2019). Service provision for at risk children under inclusive education reform in Ukraine.Kyiv: Open Society Foundation.

Borgoni, L., Petita, L., \& Barbanelli, K. (2014) Test o fmotivational orientations /adaptation for Ukraine: L. Burlachuk, Kh. Rakhubovska.GiuntiPsychometrics. Retrieved from https://giuntipsy.com.ua/

Cabinet of Ministers of Ukraine. (2016). Decree on approval the concept of the state policy realization under reforming general secondary education 'New Ukrainian School' for the period until 2029. Kiev, Ukraine: Author. Retrieved from https://osvita.ua/legislation/ Ser_osv/54258/

Cabinet of Ministers of Ukraine. (2019). Procedure of raising qualification of pedagogical and scientific-pedagogical workers dated 21.08.2019 № 800 .

Competent Educators of the 21st Century: Principles of Quality Pedagogy (2009). Retrieved from https://www.earlychildhoodworkforce.org/sites/default/files/resources/ISSA\%20Q uality-Principles\%20ENGLISH.pdf

Dumcius, R., Peeters, J., Hayes, N., VanLandeghem, G., Siarova, H., Peciukonyté, L., Ceneric, I., \& Hulpia, H. (2014). Study on the effective use of early childhood education and care (ECEC) in preventing early school leaving (ESL). Report for the European Commission DG Education and Culture. Brussels.

European Agency for Special Needs and Inclusive Education. (2012). Teacher Education for Inclusion. Profile of Inclusive Teachers. Retrieved from https://www.europeanagency.org/sites/default/files/Profile-of-Inclusive-Teachers.pdf

European Commission, New priorities for European cooperation in education and training, Communication from the Commission to the European Parliament, the Council, the European Economic and Social Committee and the Committee of the Regions. (2015). Joint Report of the Council and the Commission on the implementation of the Strategic framework for European cooperation in education and training ET2020), SWD (2015) 161 final, Brussels.

European Research Association. (2012). Inclusive education in Ukraine: achievements, problems and perspectives. Resume of analytical report based on the complex research results. Kiev: Pleyady.

Georgie, G., \& Mayer, V. (2014).Test for organizational emotional intelligence Org-EIQ / Adaptation for Ukraine: V. Klymchuk, V. Gorbunova .Giunti Psychometrics. Retrieved from https://giuntipsy.com.ua/

Grinevich, L.M. (2015). National pedagogical theory about the development of education in Ukraine in the context of European integration processes. Text in Ukrainian. The Pedagogical Process: Theory and Practice, 1-2(46-47), 5-10.

Hackman, J.R. (2002). Leading Teams: Setting the Stage for Great Performances. Boston: Harvard Business School Press.

Hackman, J.R., Wageman, R., \& Fisher, C.F. (2009). Leading teams when the time is right: Finding the bes tmoments to act. Organizational Dynamics, 38(3), 192-203. DOI:10.1016/j.orgdyn.2009.04.004 
Martynchuk et al., 2020. Ways to Increase the Inclusive Competence of Pedagogical Staff of Special Needs Support Team

Hattie, J. (2009). Visible learning: A synthesis of over 800 meta-analyses relating to achievement. Routledge. Retrieved from https://visible-learning.org/2017/05/video-johnhattie-collaborative-impact/

Haug, P. (2017). Understanding inclusive education: ideals and reality. Scandinavian Journal of Disability Research, 19(3), 206-217. DOI: 10.1080/15017419.2016.1224778

Hersh, D.J., O'Rourke, J.A., \& Lewis, A.V. (2013). CollaborationTowards Inclusion: An interprofessional learning opportunity for education and speech pathology students. Journal of Clinical Practice in Speech-Language Pathology, 15(3), 115-119.

İlik, Ş.Ş., \& Sarı, H. (2017). The training program for individualized education programs (IEPs): Its effect on how inclusive education teachers perceive their competencies in devising IEPs. Educational Sciences: Theory \& Practice, 17, 1547-1572. DOI: https://doi.org/10.12738/estp.2017.5.0424

Kolupayeva, A.A., \& Taranchenko, O.M. (2016). Inclusive education: From basics to practice. Textin Ukrainian. Kyiv: Ltd. 'ATOPOL'.

Kolupayeva, A. (2009). Inclusive education: realities and perspectives. Text in Ukrainian. Kyiv: Samit Knyha.

Kurth, J., \& Foley, J. (2014). Reframing Teacher Education: Preparing Teachers for Inclusive Education. Inclusion: December, 2(4), 286-300.

Loreman, T., McGhie-Richmond, D., Kolupayeva, A., Taranchenko, O., Mazin, D., \& Crocker, C. (2016). Canada-Ukraine collaborative initiative for inclusive education in Ukraine: Participant perspectives. School Effectiveness and School Improvement, 27(1), 24-44.

Martynchuk, O.V. (2018). Preparation of special education specialists for professional work in inclusive educational environment. Kyiv: Tsentruchbovoyiliteratury.

Piters, J. (2018). Increasing quality of early childhood education in Ukraine. Gent: VBJK.

Rotte, K. (2014). IEP Use by General and Special Education Teachers. SAGE Open, 4(2). DOI: $10.1177 / 2158244014530410$

Sofiy, N. (2017). Ukraine - ECECWorkforceProfile. In P. Oberhuemer\&I. Schreyer, Work force Profiles in Systems of Early Childhood Education and Carein Europe. Retrieved from www.seepro.eu/English/Country_Reports.htm

Stroggilos, V., \& Xanthacou, Y. (2006). Collaborative IEPs for the education of pupils with profoundand multiple learning difficulties. European Journal of Special Needs Education, 29(3), 339-349, DOI: 10.1080/08856250600810872

Strogilos, V., Stefanidis, A., \& Tragoulia, E. (2016). Co-teachers’ Attitudes towards Planning and Instructional Activities for Student swith Disabilities. European Journal of Special Needs Education, 31(3). Retrieved from https://www.tandfonline.com/ doi/full/ 10.1080/08856257.2016.1141512

Tankersley, D., Braikovich, S., \& Handze, S. (2010). Professional development tool fo rimproving the quality of work of primary school teachers. Hungary: International STEP by STEP Association.

Verkhovna Rada of Ukraine. (2017). Law of Ukraine on education. Kiev, Ukraine: Author. Retrieved from https://zakon.rada.gov.ua/laws/show/2145-19

Wageman, R., \& Hackman, J.R. (2010). What Makes Teams of Leaders Leadable? In Handbook of Leadership Theory and Practice, chapter, 17. Boston: HBRpress. 